\title{
Concordância verbal na variedade urbana do Rio de Janeiro: um estudo sobrea face fonética do morfema verbal de P6
}

DOI: http://dx.doi.org/10.21165/el.v50i3.2430

\section{Jéssica Rocha'}

\section{Resumo}

Esta pesquisa, provinda de minha Monografia de Conclusão de Curso, objetiva contribuir para os conhecimentos dos padrões de concordância em variedades do Português por meio da interface dos níveis morfossintático e fonético: investiga-se a expressão fônica do morfema verbal de terceira pessoa do plural (P6) na variedade urbana do Rio de Janeiro. A análise, que se concentra nos dados encontrados na amostra brasileira do corpus Concordância, é fundamentada pela Sociolinguística variacionista (WEINREICH; LABOV; HERZOG, 1968). Os resultados estatísticos apontam que a variação é reprimida em ambiente tônico e que, no que diz respeito aos dados átonos, a ausência do sândi e a presença de vogal nasal em contexto posterior favorecem as expressões mais fortes. No nível extralinguístico, assumem essa posição a faixa etária mais jovem, o nível de escolaridade mais alto e a localidade de maior prestígio cultural e socioeconômico.

Palavras-chave: fonética; morfossintaxe; interface; concordância verbal; variação linguística

1 Universidade Federal do Rio de Janeiro (UFRJ), Rio de Janeiro, Rio de Janeiro, Brasil; jamr.jessica@gmail.com; https://orcid.org/0000-0001-6550-3184 


\title{
Verbal agreement in the urban variety of Rio de Janeiro: a study on the phonetic face of P6 verbal morpheme
}

\begin{abstract}
This research, resulting from my Undergraduate Thesis, aims to contribute to the knowledge of the agreement patterns in varieties of Portuguese through the interface of the morphosyntactic and phonetic levels: the phonic expression of the plural third-person (P6) verbal morpheme in the urban variety of Rio de Janeiro is investigated. The analysis, which focuses on the data found in the Brazilian sample of the Concordance corpus, is supported by variationist sociolinguistics (WEINREICH; LABOV; HERZOG, 1968). The statistical results show that the variation is repressed in the tonic environment and that, concerning unstressed data, the absence of sandhi and the presence of nasal vowel in a posterior context favor the strongest expressions. At the extra-linguistic level, this position is assumed by the youngest age group, the highest level of education and the location of greatest cultural, and socioeconomic prestige.
\end{abstract}

Keywords: phonetic; morphosyntax; interface; verbal agreement; linguistic variation.

\section{Introdução}

A pesquisa que ora se apresenta tem por objetivo contribuir para o conhecimento dos padrões de concordância em variedades do Português através de um olhar específico sobre o fenômeno: analisam-se as realizações fonéticas da desinência verbal de terceira pessoa do plural (P6) na variedade urbana carioca do Português Brasileiro (PB). O objeto, situado entre os níveis linguísticos morfossintático e fonético, é de natureza altamente variável. A título de exemplificação, observem-se três maneiras encontradas da expressão

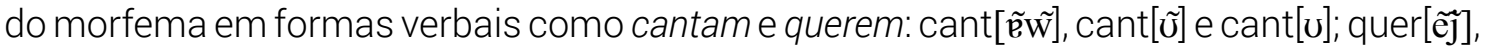
quer[I] e quer[I].

A necessidade desta investigação relaciona-se ao conceito da saliência fônica, proposto como princípio linguístico por Lemle e Naro (1977), que estabelece que a marca explícita da concordância é regulada pela (alta ou baixa) diferenciação entre a forma verbal plural e a singular: a ausência de marca atingiria em maior frequência pares opositivos como canta/cantam e em menor frequência pares do tipo é/são, pois neste último há grande diferenciação fonética entre as formas e, por isso, o falante/ouvinte tenderia a evitar o apagamento da marca. A relevância da variável em estudos variacionistas sobre a concordância verbal indica que, em linhas gerais, há, no $\mathrm{PB}$, uma estreita relação entre a marcação explícita de plural e o grau de diferenciação entre a forma plural e a singular respectiva. 
Diante disso, este trabalho apresenta uma análise empírica, com base nos preceitos teórico-metodológicos da Sociolinguística variacionista (WEINREICH; LABOV; HERZOG, 2006), das expressões fonéticas que marcam a expressão do plural em dados de concordância verbal. Para isso, faz-se uso da amostra brasileira do corpus Concordância, organizado pelo projeto então intitulado "Estudo comparado dos padrões de concordância em variedades africanas, brasileiras e europeias do Português". O objetivo central da análise, além da própria descrição do fenômeno na variedade urbana carioca do Português Brasileiro (PB), é contribuir, por meio da interface dos níveis fonético e morfossintático, para o futuro refinamento do controle da saliência fônica na variação da concordância verbal e, assim, com os conhecimentos dos padrões de concordância nas variedades do Português.

Sobre o comportamento do fenômeno, tendo em vista os objetivos supracitados, foram consideradas as seguintes hipóteses: a) nos termos de Labov (2003), que a expressão do morfema número-pessoal de terceira pessoa do plural se revelasse um fenômeno variável; b) que se mostrassem os mais fortes condicionadores, na esfera social, a localidade, o nível de escolaridade e a faixa etária do informante e, na linguística, as variáveis do nível fonético (tonicidade da sílaba da desinência, a incidência de sândi e o contexto fonético subsequente à forma verbal); e c) que se mostrassem favoráveis às realizações foneticamente mais brandas as vogais nasais em contexto posterior e as formas verbais que apresentam alterações além da terminação na passagem do singular para o plural, como o pretérito perfeito (na passagem de comeu para comeram, por exemplo, ocorrem a queda da semivogal, o acréscimo do /R/ e o aumento do número de sílabas).

\section{Fundamentação teórico-metodológica}

Os autores responsáveis pela introdução da variável saliência fônica nos estudos brasileiros variacionistas sobre a concordância verbal, Lemle e Naro (1977), propuseram que esse controle fosse realizado por meio de uma escala que vai do nível mais baixo ao mais alto de diferenciação singular/plural (e, assim, da tendência mais baixa à mais alta de aplicação da marca explícita da concordância) considerando fatores como acento, tempo/modo verbal e forma do verbo. Posteriormente, a escala que os autores apontaram como mais condizente com os resultados estatísticos foi reestruturada por Naro (1981), o que originou a hierarquia mais utilizada em estudos da regra morfossintática - não por isso livre de novas questões, como as levantadas por Guy (1981), que defende que o acento não deve ser um parâmetro considerado para uma escala de saliência fônica, sob o argumento de que a tonicidade apenas regularia a possibilidade de desnasalização.

No entanto, o controle da variável em estudos da concordância verbal enfrentou alguns impasses que ferem o entendimento do conceito como princípio. São exemplos disso os seguintes fatos: a organização dos níveis não se mostrou compatível com os resultados de Monguilhott $(2001,2009)$, principalmente no que se refere aos dados do nível de 
escolaridade mais alto; e a variável não foi considerada como estatisticamente relevante em Barreto (2014), que analisou dados do Português Europeu. Conforme assinalam Vieira, Brandão e Gomes (2015) e Chaves (2014), que pensam criticamente sobre a organização das escalas e analisam especificamente o aspecto fonético da marcação da concordância, as oposições levadas em conta para a estruturação das escalas ficaram no campo teórico, se fazendo necessária a consideração da produção real dos falantes para, então, compreender a relação entre a marca explícita da concordância e as diferenças sonoras entre singular e plural.

Sendo assim, este trabalho entra na discussão de modo a apresentar uma análise das expressões fônicas do morfema verbal de P6 com base em dados empíricos, tratados segundo a perspectiva da Sociolinguística de orientação laboviana (WEINREICH; LABOV; HERZOG, 1968). Desse aporte teórico-metodológico adotado, privilegiam-se, além da concepção de língua como um sistema que reflete a diversidade social, a) a premissa da heterogeneidade ordenada - que compreende a variação como um fator que, muito antes de ter qualquer relação com o caos, confere dinamicidade ao sistema linguístico; e b) os problemas das restrições e do encaixamento linguístico e social - estuda-se a interação do objeto linguístico com fatores sociais e outros fenômenos internos à língua, uma vez que se trata de um fenômeno situado no nível fonético determinado por (e possivelmente determinante de) uma regra morfossintática, a concordância verbal.

\section{Metodologia: a amostra analisada e as etapas do trabalho}

Esta pesquisa fez uso do Corpus Concordância, que consiste em entrevistas sociolinguísticas realizadas entre os anos 2008 e 2010 por membros do projeto "Estudo dos padrões de concordância em variedades africanas, brasileiras e europeias do Português", ao qual está integrada esta investigação. Os diálogos, que têm em torno de 40 minutos e são guiados pelos documentadores de modo a estimular a produção oral, perpassam diversos assuntos - como pontos positivos e negativos do bairro em que reside o informante, política, memórias de infância, sonhos e pluralidade linguística².

Conforme sistematizado no Quadro 1, para esta análise foram exploradas 12 gravações de falantes residentes em cada uma das regiões controladas: Copacabana, bairro da Zona Sul do município do Rio de Janeiro - uma região de prestígio - e Nova Iguaçu, município da Baixada Fluminense, que tem sua imagem ligada a grandes problemas sociais que contribuem para o crescimento da violência, como a escassez de serviços públicos e de infraestrutura urbana. Cada uma das células indicada a seguir é representada por dois

2 Todas as entrevistas consideradas para a investigação estão disponíveis, em áudio e transcrição grafemática, no site https://corporaport.letras.ufrj.br/. O acesso aos arquivos é gratuito, sendo exigido apenas o cadastro na plataforma, que, no presente momento, conta também com amostras do Português Europeu e do Português de Moçambique. 
informantes, um de cada localidade, e o total de 24 sujeitos está organizado por: a) sexo - homem e mulher; b) nível de escolaridade - nível 1 para os que estudaram até o Ensino Fundamental, 2 para os que estudaram até Ensino Médio e 3 para os estudaram até o Ensino Superior; e c) faixa etária - neste caso, a faixa A, que compreende os falantes mais jovens, de 18 a 35 anos, e a faixa $C$, referente aos falantes mais velhos, de 56 a 75 anos.

Quadro 1. Amostra analisada: faixas A e C das regiões de Copacabana e Nova Iguaçu

\begin{tabular}{|c|c|c|}
\hline \multirow{2}{*}{ Nível de escolaridade } & Faixa A (18 a 35 anos) & Faixa C (56 a 75 anos) \\
\hline \multirow{2}{*}{ Nível 1 (Ensino Fundamental) } & $\mathrm{A}-1-\mathrm{H}$ & $\mathrm{C}-1-\mathrm{H}$ \\
\cline { 2 - 3 } & $\mathrm{A}-1-\mathrm{M}$ & $\mathrm{C}-1-\mathrm{M}$ \\
\hline \multirow{2}{*}{ Nível 2 (Ensino Médio) } & $\mathrm{A}-2-\mathrm{H}$ & $\mathrm{C}-2-\mathrm{H}$ \\
\cline { 2 - 3 } & $\mathrm{A}-2-\mathrm{M}$ & $\mathrm{C}-2-\mathrm{M}$ \\
\hline \multirow{2}{*}{ Nível 3 (Ensino Superior) } & $\mathrm{A}-3-\mathrm{H}$ & $\mathrm{C}-3-\mathrm{H}$ \\
\cline { 2 - 3 } & $\mathrm{A}-3-\mathrm{M}$ & $\mathrm{C}-3-\mathrm{M}$ \\
\hline
\end{tabular}

Fonte: Elaboração própria

O tratamento dos dados foi iniciado pela coleta, na transcrição grafemática, de todas as ocorrências de verbos na terceira pessoa do plural ligados a um sujeito plural, seguida pela transcrição fonética de cada uma dessas formas verbais e da palavra subsequente. O passo seguinte foi organizar e observar os dados segundo a tonicidade e o contexto fônico posterior, o que foi fundamental para a formulação das hipóteses. Depois, os dados foram codificados segundo variáveis sociais e linguísticas: a) do primeiro grupo fazem parte localidade, faixa etária, nível de escolaridade e sexo (fatores que compõem o perfil do informante); b) do segundo, tonicidade da sílaba da desinência (tônica ou átona), contexto fônico subsequente (consoante nasal, consoante oral, vogal nasal, vogal oral ou

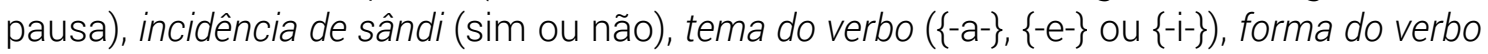
(regular, irregular apenas no paradigma ou irregular no par opositivo) e tempo/modo verbal (todos os encontrados: presente, pretérito perfeito, pretérito imperfeito, futuro e futuro do pretérito do indicativo; presente, pretérito imperfeito e futuro do subjuntivo; além da estrutura infınitiva). Por fım, foi feita a quantificação dos dados no programa de análise estatística Goldvarb X (SANKOFF; TAGLIAMONTE; SMITH, 2005).

Vale destacar, antes de partir para a apresentação dos resultados, que, além de uma quantificação geral, considerando cada variante isoladamente, foram realizadas, também, duas análises com as variantes divididas em grupos: a) padrão e não padrão, sendo da

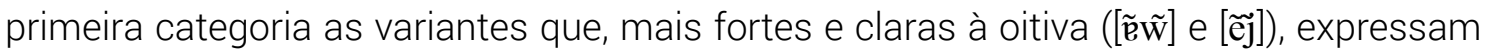
plenamente a noção de plural, e da segunda as que são frutos de processos fonéticos de enfraquecimento; b) nasal e não nasal, sendo o primeiro grupo para as realizações que apresentam o traço de nasalidade e o segundo para as que não o apresentam. 


\section{Resultados}

A exposição dos resultados, nesta seção, organizada de acordo com as rodadas estatísticas realizadas: primeiro, apresenta-se a distribuição geral dos resultados, considerando todas as realizações encontradas do morfema verbal de terceira pessoa do plural em dados de concordância entre sujeito e verbo3; depois, apresentam-se os resultados obtidos na primeira análise multivariada realizada no programa estatístico, padrão versus não padrão; e, por último, apresentam-se os resultados referentes à segunda rodada binária, em que se contrapõem as realizações do tipo nasal às do tipo não nasal.

\section{Distribuição geral dos dados}

Na Tabela 1, expõe-se a distribuição geral dos dados, divididos por tema - apenas para uma visualização mais clara - e tonicidade, condicionamento de relevância notável já nesta primeira abordagem.

Vale colocar, de antemão, que foram consideradas as 9 variantes mais recorrentes no corpus, que ofereceu um total de 2072 ocorrências. As (possíveis) expressões [[õ] [o], [ẽ] e [e]] foram excluídas da análise não somente pelo limite de variantes que pode ser admitido pelo Goldvarb X, mas também pelo seu comportamento esporádico e, na quase totalidade dos casos, associado a contextos de sândi, como no exemplo a seguir. Nesses casos, não se pode assegurar se há realmente uma expressão fonética da desinência de P6 ou se houve queda da vogal (ou do ditongo) da desinência e, restando uma consoante (flutuante), o processo de ressilabação com a vogal da palavra posterior.

1. eles tiver[o]portunidade (COP C-1-H)

Tabela 1. Distribuição geral dos dados: a expressão fonética da desinência verbal de P6 em sílabas átonas e tônicas das três conjugações

\begin{tabular}{c|c|c|c|c}
\hline \multirow{2}{*}{ Variante } & \multicolumn{2}{|c|}{$1^{\text {a }}$ conjugação } & \multicolumn{2}{c}{$2^{\mathrm{a}}$ e 3a conjugações } \\
\cline { 2 - 5 } & Átonas & Tônicas & Átonas & Tônicas \\
\hline$[\tilde{\mathrm{x}} \tilde{\mathrm{w}}]$ & $199 / 709(28,1 \%)$ & $108 / 174(62,1 \%)$ & $124 / 631(19,7 \%)$ & $260 / 331(78,5 \%)$ \\
\hline$[\tilde{\mathrm{e}}]$ & $18 / 709(2,5 \%)$ & $7 / 174(4 \%)$ & $12 / 631(1,9 \%)$ & $18 / 331(5,4 \%)$ \\
\hline$[\mathfrak{e}] /[\mathrm{a}]$ & $164 / 709(23,1 \%)$ & $40 / 174(23 \%)$ & $52 / 631(8,2 \%)$ & - \\
\hline
\end{tabular}

3 Sendo o objetivo do trabalho descrever, na variedade urbana carioca do PB, como a concordância verbal é expressa, optou-se por eliminar as formas verbais em que não há dúvidas sobre o cancelamento da regra de marcação de plural, tais como, é, cantou, fez e quis - estruturas evidentemente distantes de suas respectivas formas plurais são, cantaram, fizeram e quiseram. 


\begin{tabular}{|c|c|c|c|c|}
\hline [õw] & $47 / 709(6,6 \%)$ & $15 / 174(8,6 \%)$ & $34 / 631(5,4 \%)$ & $44 / 331(13,3 \%)$ \\
\hline [ũ] & 129/709 (18,2\%) & $4 / 174(2,3 \%)$ & 76/631 (12\%) & 9/331 (2,7\%) \\
\hline [u] & $83 / 709(11,7 \%)$ & - & $44 / 631(7 \%)$ & - \\
\hline [ẽj] & $25 / 709(3,5 \%)$ & - & 120/631 (19\%) & - \\
\hline [I] & $24 / 709(3,4 \%)$ & - & $60 / 631(9,5 \%)$ & - \\
\hline [I] & $20 / 709(2,8 \%)$ & - & 109/631 (17,3\%) & - \\
\hline
\end{tabular}

Fonte: Elaboração própria

O que se deve destacar desses resultados, em primeiro lugar, é que as possibilidades de realização do morfema número-pessoal de P6 em dados de sílaba átona são muito mais numerosas do que em dados de sílaba tônica. Note-se que, em formas verbais das três conjugações, todas as nove variantes são encontradas no contexto átono; em ambiente tônico, diferentemente, são encontradas apenas cinco em dados de primeira conjugação e quatro em dados de segunda e terceira.

Em sílabas átonas de verbos de primeira conjugação, como em olham e andavam, a

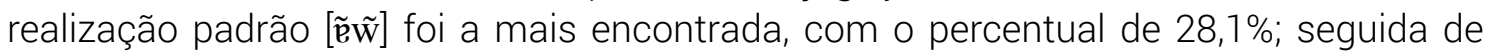

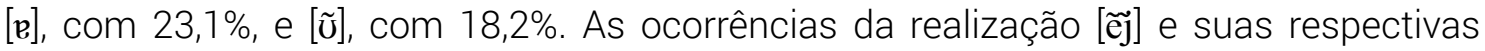
reduções ([ٓ] e [I]) em verbos de primeira conjugação correspondem aos modos verbais subjuntivo (tempos presente, pretérito imperfeito e futuro), como em olhem, andassem, e infinitivo (flexionado), como em colocarem. Observe-se que, nesses casos, os valores percentuais são muito próximos: respectivamente, 3,5\%, 3,4\% e 2,8\%.

Nos dados átonos de tema em $\{-\mathrm{e}-\}$ e $\{-\mathrm{i}-\}$, como em comem e quiseram, as realizações

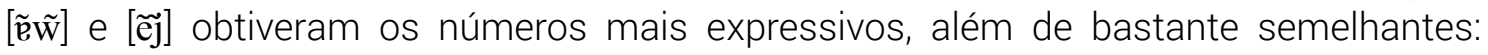
respectivamente, 19,7\% e 19\%. Depois, estão as suas reduções [I], com 17,3\%, e [ũ], com $12 \%$.

Cabe frisar, também, que as realizações [e] e [I] são as mais próximas das estruturas singulares e, exceto em dados do tipo falaram e conseguirem - em que a marca da concordância não se limita à expressão da desinência -, provavelmente seriam entendidas como cancelamento da marca em estudos clássicos de concordância verbal. Foram, entretanto, consideradas neste estudo porque, uma vez que se deseja investigar a força do componente fonético sobre a regra morfossintática, é necessário entender, antes de apontá-las como estruturas sinalizadoras de ausência de marca explícita da concordância, até que ponto o contexto fonético que as circunda é favorável a seu aparecimento.

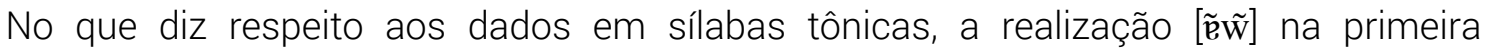
conjugação foi a predominante, com $62,1 \%$, seguida da variante [a], com $23 \%$. Essas 
ocorrências foram encontradas nas formas verbais estão e dão e os dados de [a] não foram considerados como cancelamento da marca de concordância por conta da sutil diferença atribuída exclusivamente à nasalidade. No fluxo da fala - principalmente em se tratando de gravações feitas em lugares como farmácia, residência do informante e escola, que contam com a presença de outras pessoas e de sons naturais a esses ambientes -, a diferença entre presença e ausência do traço não é tão clara. Além disso, a forma verbal estão é frequentemente produzida como tão, o que faz a maioria desses dados corresponder a monossílabos, sendo a precisão ainda mais difícil.

Em ocorrências tônicas de segunda e terceira conjugações - todas as variantes foram

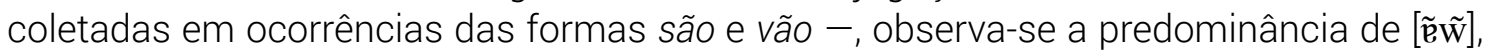
com $78,5 \%$, seguida do resultado referente a [õ̃w], com apenas 13,3\%. Nota-se, com esse resultado e o da primeira conjugação, que os percentuais da comparação entre as duas realizações mais utilizadas são bastante discrepantes.

Atestado que o fenômeno é resistente à variação quando em sílaba tônica, optou-se, para a quantificação dos dados em análises binárias no Goldvarb X, pela concentração na variabilidade encontrada em sílabas átonas. As análises que se descrevem a seguir, portanto, além de serem caracterizadas pelos agrupamentos das variantes, levam em conta apenas os dados coletados neste último contexto. Em termos de síntese e, ao mesmo tempo, demonstração da interface entre os níveis fonético e morfossintático, são apresentados, neste trabalho, os resultados referentes às variáveis do primeiro nível que sobressaíram em cada uma das análises e os referentes às variáveis sociais.

\section{Análise padrão versus não padrão}

Das quatro primeiras variáveis selecionadas - considerando as extralinguísticas e as fonéticas - na rodada em que foram contrapostas as variantes padrão e não padrão (em ordem de seleção: faixa etária, incidência de sândi, localidade e nível de escolaridade), apenas uma é de natureza linguística. Isso mostra que o fenômeno, apesar de ser ainda pouco descrito empiricamente e, ao que se supõe, não estar sob o controle consciente dos falantes, está sistematicamente organizado na estrutura social. Tomando como valor de aplicação o tipo padrão, obtiveram-se, nesta rodada, input de .28 e significância de .00.

\section{a) Variáveis extralinguísticas}

A seguir, o Gráfico 1 expõe os resultados referentes à primeira variável do nível social selecionada pelo programa estatístico: faixa etária do informante. A hipótese postulada para esse controle foi de que os falantes mais jovens, mais adeptos a inovações, se mostrariam favorecedores do enfraquecimento fonético da marca explícita da concordância. 
Gráfico 1. Aplicação da variante padrão em função da variável faixa etária

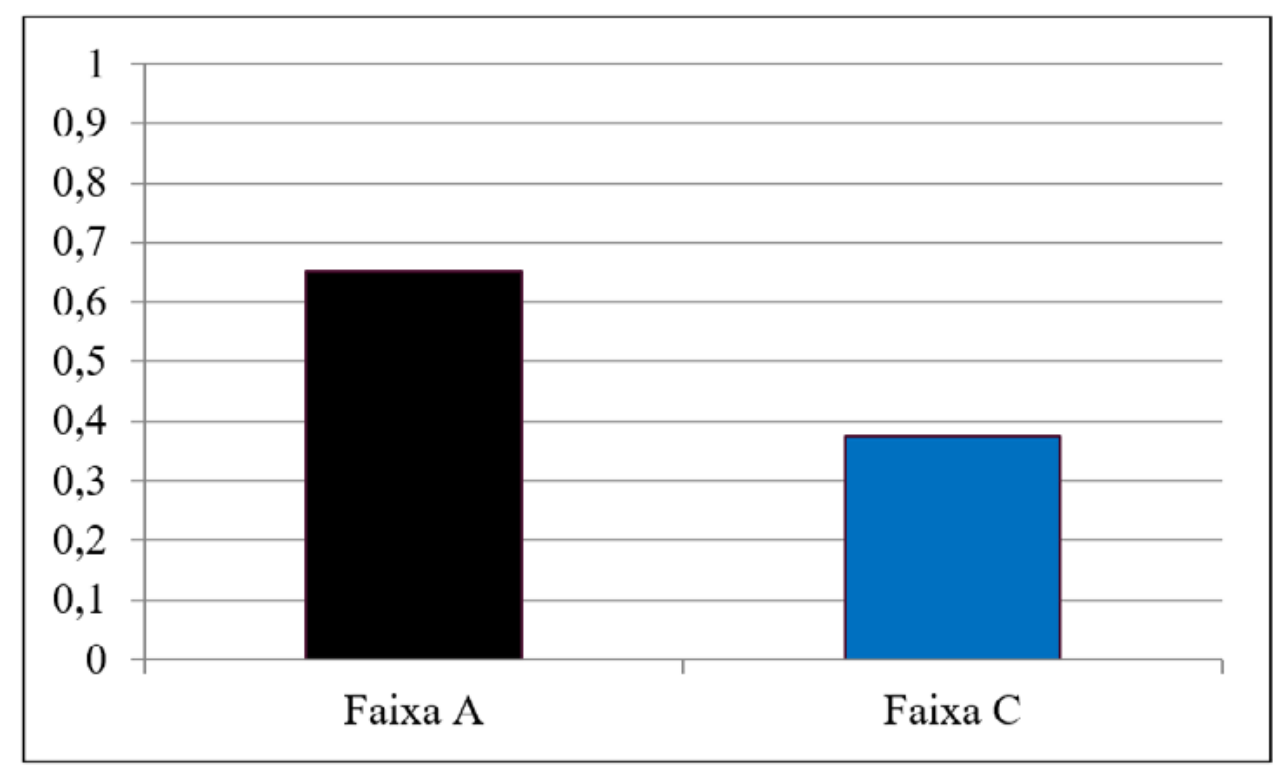

Fonte: Elaboração própria

Percebe-se que, ao contrário do esperado, com peso relativo de .65 , os mais jovens favoreceram as variantes padrão e os mais velhos, com .37, a desfavoreceram.

Esses primeiros resultados já dão sinais importantes sobre a interface entre fonética e morfossintaxe para o fenômeno da concordância, pois, ainda que a expressão fonética da concordância não esteja no nível da consciência dos falantes como a oposição morfossintática de presença versus ausência de marca explícita, os resultados mostramse compatíveis com o que se observa em estudos sobre a concordância verbal na área urbana do Rio de Janeiro. Os estudos de Naro e Scherre $(2003,2010)$, por exemplo, que tratam do fenômeno morfossintático em dois pontos distintos da linha do tempo, atestam o aumento das taxas de concordância - o que se pode observar, também, pela comparação entre as faixas etárias.

Apresentam-se, no Gráfico 2, os resultados referentes ao grupo de fatores localidade, diante do qual foi esperado favorecimento de realizações padrão por parte da região de maior prestígio, Copacabana. 
Gráfico 2. Aplicação da variante padrão em função da variável localidade

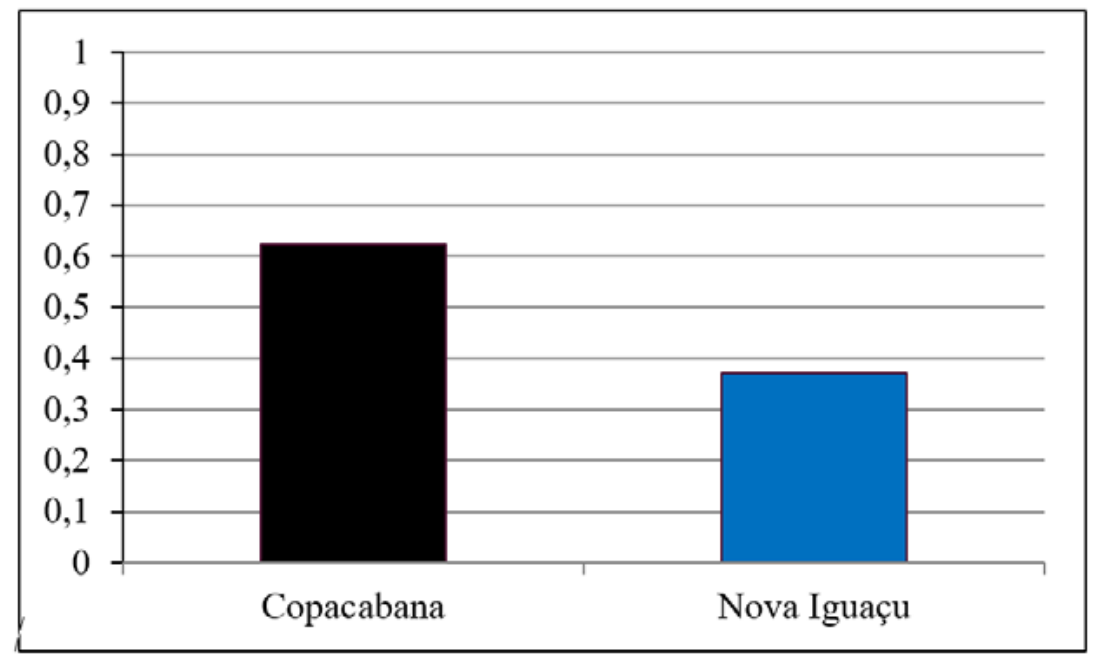

Fonte: Elaboração própria

Verificou-se, desta vez, a confırmação da hipótese levantada: os dados provenientes da Zona Sul do Rio de Janeiro foram do tipo mais padrão que os coletados nas entrevistas da Baixada Fluminense. Com peso relativo de .64, Copacabana mostrou-se favorecedora das expressões do tipo padrão e Nova Iguaçu, com índice de .37, mostrou-se desfavorecedora.

Observem-se, a seguir, os resultados correspondentes à terceira variável extralinguística selecionada na rodada padrão versus não padrão, que reflete o controle do nível de escolaridade do informante. Para essa variável, hipotetizou-se que o fator da escolarização atuasse de modo a aumentar a tendência a variantes foneticamente mais fortes (neste caso, as do tipo padrão).

Gráfico 3. Aplicação da variante padrão em função da variável nível de escolaridade

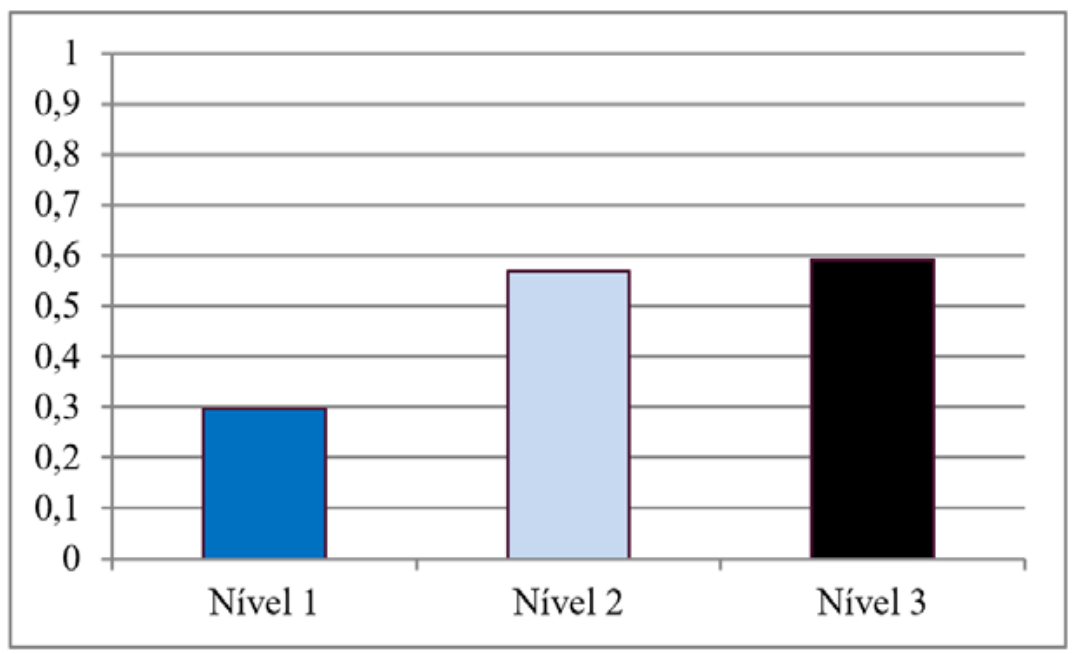

Fonte: Elaboração própria 
Observa-se que, quanto ao nível de escolaridade, o fenômeno se distribuiu de maneira escalar: quanto maior o nível de instrução formal, maior a preferência por expressões padrão, sendo a maior diferença entre os usos a que existe entre os níveis 1 e os demais, que apresentam comportamento similar. O nivel de escolaridade 1 , que obteve peso relativo de .29, mostrou-se desfavorecedor de realizações padrão e os níveis 2 e 3, que obtiveram pesos relativos de, respectivamente, .56 e .59, mostraram-se favorecedores.

b) Variável linguística

A única variável pertencente ao nível fonético - e primeira de natureza linguística selecionada como relevante para a aplicação das variantes do tipo padrão foi incidência de sândi, para a qual foi levantada a hipótese de que a ocorrência do processo geraria formas foneticamente reduzidas. Os resultados obtidos são representados pelo Gráfico 4.

Gráfico 4. Aplicação da variante padrão em função da variável incidência de sândi

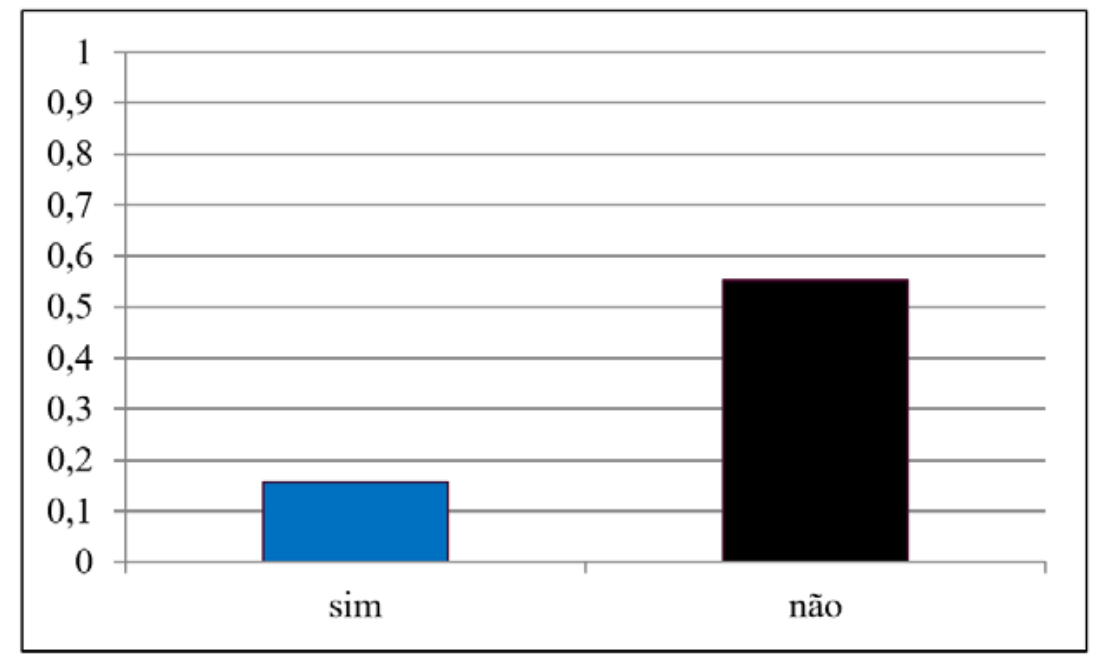

Fonte: Elaboração própria

Verificou-se que o comportamento do fenômeno foi conforme o hipotetizado: variantes padrão tendem a não coincidir com o sândi. A ocorrência do processo mostrou-se desfavorecedora da realização padrão (peso relativo de .15) e sua não ocorrência, por sua vez, faz aumentar a tendência à realização padrão.

Em 2 e 3, exemplificam-se variantes padrão sem a incidência de sândi e, em 4 e 5, realizações não padrão que se fundiram ao elemento fônico posterior. 


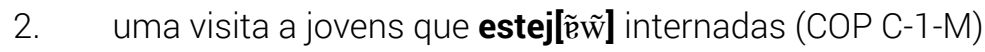

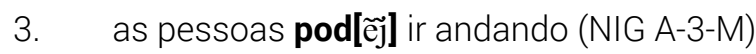

4. os filho dele têm/ pux[ũ](um) pouco aquele sotaque (NIG A-1-H)

5. se as pessoas se mantiver[ja](a)comodadas (COP A-2-H)

\section{Análise nasal versus não nasal}

A organização e o tratamento dos dados segundo os tipos padrão e não padrão ocorreu desde o início desta investigação. A separação das variantes conforme a presença ou ausência da nasalidade, no entanto, partiu da surpresa causada pelo descarte da variável contexto subsequente na primeira rodada multivariada, pois é natural que fenômenos do nível fonético, sobretudo envolvendo a presença e a ausência do traço de nasalidade, recebam influência do contexto posterior. Percebeu-se que, em um primeiro momento, se relacionou a nasalidade às realizações padrão - de fato, a nasalidade é uma característica importante dessas variantes, mas também está presente nas demais formas dispostas aos falantes no sistema linguístico. Assim, pareceu mais coerente com a variabilidade do fenômeno (mais alta do que se esperava) que o controle da variável fosse harmonizado com a presença ou a ausência do traço.

Desta vez, a variável contexto fônico subsequente, além de ter sido selecionada, foi a variável fonética que mais demonstrou relevância estatística para o fenômeno investigado. O input e a significância obtidos nesta rodada, de que a variante nasal foi o valor de aplicação, foram de, respectivamente, 68 e .01 .

a) Variáveis extralinguísticas

O condicionamento selecionado em primeiro lugar foi, novamente, de natureza extralinguística. Representam-se, no Gráfico 5, os resultados referentes à variável nível de escolaridade. 
Gráfico 5. Aplicação da variante nasal em função da variável nível de escolaridade

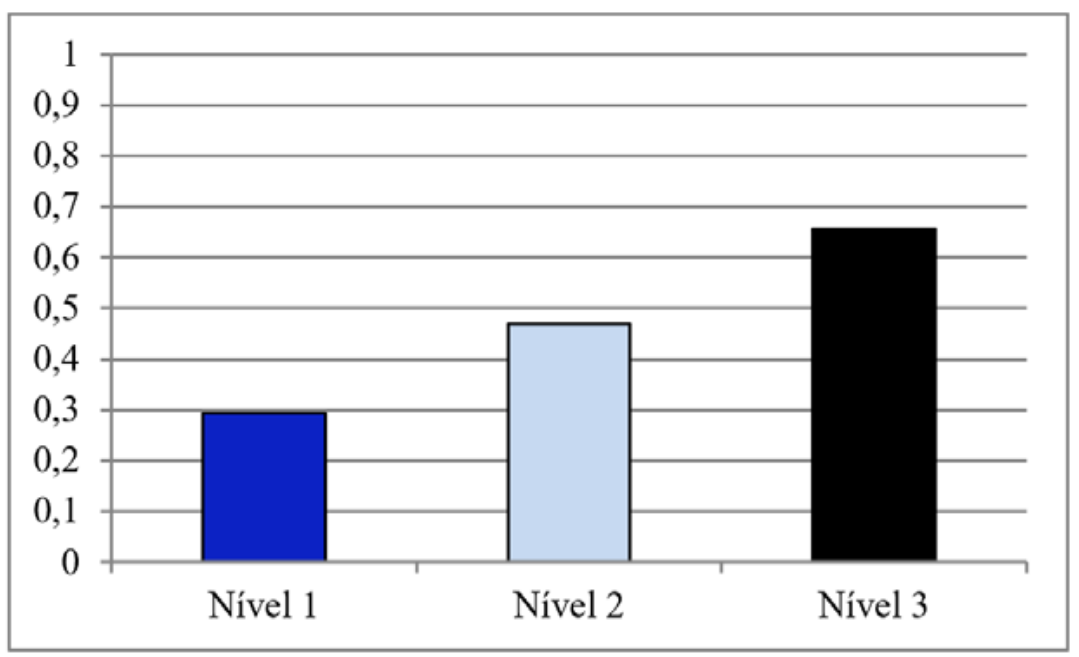

Fonte: Elaboração própria

Observa-se que o uso das realizações com traço nasal também cresce conforme aumenta o nível de escolaridade do participante: o nivel 1 de escolaridade desfavoreceu as variantes nasais (P.R. .29), ao passo que o nível 3 as favoreceu (P. R. .65), e o nível 2 ficou em posição intermediária (P.R. .47). Desta vez, a distribuição se mostrou mais bem distribuída de forma escalar, tendo ficado mais evidentes as diferenças entre os resultados referentes a indivíduos que estudaram até o Ensino Médio e os que cursaram o Ensino Superior.

O gráfico a seguir ilustra os resultados obtidos para a variável faixa etária, que se mostrou, mais uma vez, uma das mais influentes para o fenômeno investigado.

Gráfico 6. Aplicação da variante nasal em função da variável faixa etária

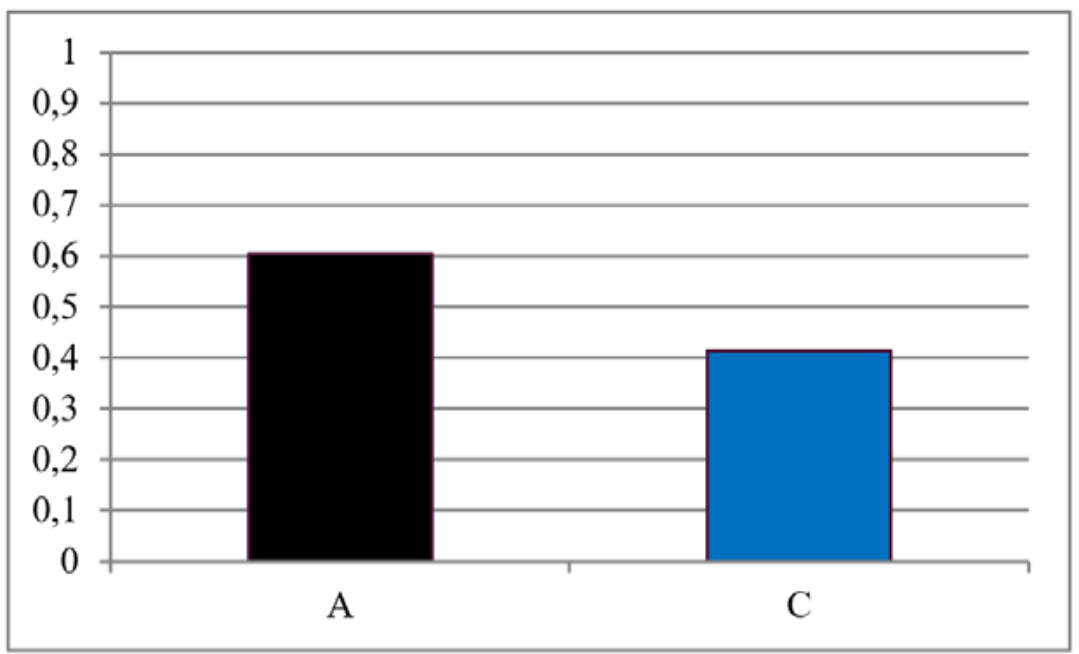

Fonte: Elaboração própria 
Novamente, esse condicionamento foi de encontro ao que se tinha como expectativa: a faixa $A$, referente aos falantes mais jovens, favoreceu as realizações mais fortes, apresentando peso relativo de .60, e a faixa $C$, referente aos mais velhos, as desfavoreceu, apresentando peso relativo de .41. O Gráfico 6 permite visualizar a disparidade que, embora menor do que a da rodada anterior, existe entre os fatores.

b) Variáveis linguísticas

A variável contexto subsequente, descartada na rodada anterior, foi a primeira de ordem linguística selecionada desta vez. As hipóteses levantadas para esse controle foram as seguintes: a) os contextos com traço de nasalidade (consonantais e vocálicos) favoreceriam as expressões do tipo nasal; e b) o contexto vogal oral favoreceria as realizações não nasal. O gráfico 7 representa os resultados alcançados.

Gráfico 7. Aplicação da variante nasal em função da variável contexto subsequente

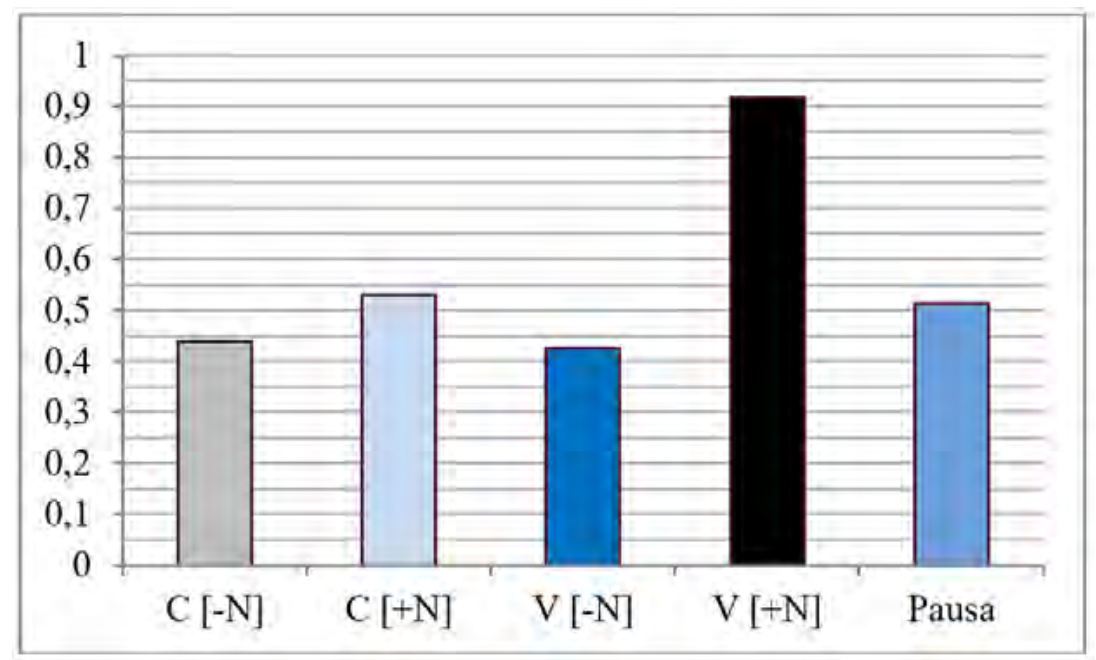

Fonte: Elaboração própria

Conforme demonstrado pelo gráfico, apenas o contexto vogal nasal se mostrou realmente favorecedor das realizações com traço de nasalidade. Os demais contextos apresentaram certa neutralidade entre si, com pesos relativos bastante próximos se comparados ao do primeiro contexto mencionado: o fator consoante oral atingiu o peso relativo de .43; consoante nasal, de .53; vogal oral, .42; e pausa, .51. Esse resultado não correspondeu à hipótese levantada para o controle da variável, pois o peso relativo atribuído ao contexto consoante nasal foi muito mais próximo dos resultados dos demais fatores do que do outro contexto marcado pelo traço, vogal nasal, que, por sua vez, parece ser o único ambiente posterior decisivo para o aparecimento de variantes foneticamente mais fortes do morfema verbal de P6. Isso pode estar diretamente ligado à ocorrência de sândi externo, mas a possível relação entre essas variáveis ainda precisa ser analisada com o devido cuidado. 
Os cinco contextos fônicos posteriores considerados estão representados nos exemplos a seguir, na ordem em que aparecem no gráfico: em 6, observa-se uma ocorrência de expressão não nasal diante de uma consoante oral; em 7, uma de nasal diante de uma consoante nasal; em 8, uma realização não nasal antes de uma vogal oral; em 9, um caso de nasal que antecede uma vogal nasal; e, em 10, uma realização nasal seguida de pausa (representada graficamente pelas reticências).

6. pessoas assim... que não sab[I] ler e escrever (NIG A-1 M)

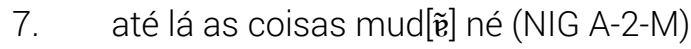

8. amigos que desde pequenos que acompanhar[u] eles (COP C-3-M)

9. pra pegar dinheiro e eles ir[i] (em)bora... (NIG A-3-M)

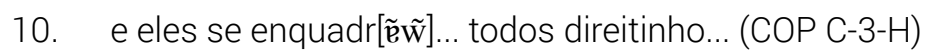

Por fim, foi selecionada também, na rodada nasal vs. não nasal, a variável incidência de sândi. O gráfico 8 representa os resultados correspondentes a esse condicionamento.

Gráfico 8. Aplicação da variante nasal em função da variável incidência de sândi

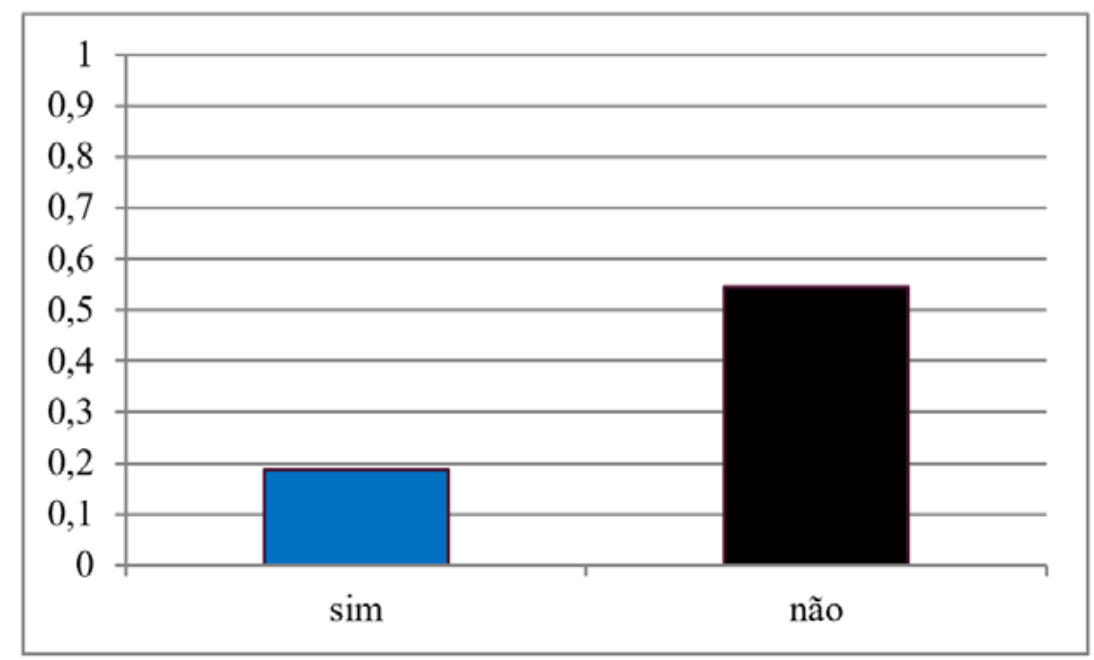

Fonte: Elaboração própria

Assim como observado na rodada anterior, embora com pesos relativos mais próximos, a incidência de sândi desfavorece a variante tomada como valor de aplicação, demonstrando provocar o enfraquecimento da expressão fonética do morfema responsável pela marca explícita da concordância verbal de P6. Quando o processo não ocorre, o traço de nasalidade é favorecido. Os pesos relativos foram de, respectivamente, . 18 e .54.

Em 11, exemplifica-se uma variante nasal em caso de não ocorrência de sândi e, em 12, uma variante não nasal em caso de detecção do processo. 
11. eles fech[õw] até a porta (COP C-7-M)

12. os pais deles se separar[a](a)gora há pouco tempo... (NIG A-1-H)

\section{Conclusão}

Na variedade brasileira do Português ou, mais especificamente, a da região metropolitana do Rio de Janeiro, a realização fônica da desinência verbal de terceira pessoa do plural mostrou-se uma regra altamente variável: foram encontradas, no corpus investigado, 13 expressões fonéticas do morfema (desse total, fez-se um recorte das 9 mais recorrentes, nas quais se concentrou a análise aqui apresentada).

Em resumo, observou-se, através da análise estatística, que grupos de fatores extralinguísticos atuam fortemente sobre o fenômeno: há um aumento do número de realizações padrão e nasal de acordo com a escolarização e a idade do informante, sendo os mais cultos e jovens os que favorecem esses dois grupos da variável dependente - o que permite afirmar, portanto, que meios urbanos favorecem cada vez mais não só a marcação de plural, mas a sua expressão foneticamente mais forte; no que diz respeito à localidade em que reside o indivíduo, a região de maior prestígio sociocultural, Copacabana, mostra-se favorecedora das variantes dos tipos padrão e nasal - resultado que reforça a pressão social exercida sobre o fenômeno da concordância mesmo em sua expressão fonética.

Dentre as variáveis linguísticas, das quais se destacaram as do nível fonético, observouse, em primeiro lugar, que sílabas tônicas são resistentes à variação e que as realizações do tipo padrão são as prototípicas nesse contexto. Em rodadas multivariadas, em que foram consideradas apenas os dados com a desinência de P6 em sílabas átonas, ficou comprovado que o sândi é desfavorecedor de realizações padrão e nasal e que a presença de uma vogal nasal em posição imediatamente posterior à forma verbal é fortemente favorecedora da manutenção do traço na realização fonética do morfema. Essas constatações evidenciam a interface entre os níveis morfossintático e fonético, pois a nasalidade, que é sensível ao contexto subsequente e à ocorrência de sândi, é um

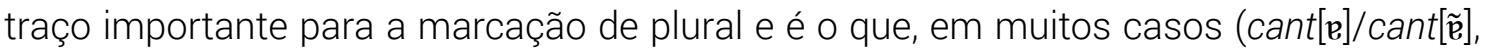
consegu[I]/consegu[I] $]$ ), assegura a explicitude da concordância.

A respeito do contexto circunvizinho à desinência de $\mathrm{P} 6$, considera-se importante observar a relação entre contexto fônico subsequente e incidência de sândi e, ainda, analisar o elemento anterior à expressão do morfema. O par opositivo pode/podem, por exemplo, na variedade carioca não tem sua diferença marcada apenas pela terminação: na forma verbal singular, realiza-se o fonema /d/ como uma africada e, na forma plural, como oclusiva. Fazer esse controle em trabalhos futuros parece um passo importante para reavaliar os níveis de saliência fônica e sua aplicação. 
O trabalho aqui apresentado, não obstante seu caráter inicial, mostrou-se produtivo no sentido de aprofundar uma das faces do fenômeno da concordância verbal: a expressão fonética da desinência de terceira pessoa do plural. A relevância da investigação pode ser aferida em termos metodológicos, no sentido de fazer repensar os expedientes gramaticais que garantem a identificação do traço de concordância, e, ainda, em termos descritivos, visto que demonstra alta sistematicidade e relevância de variáveis sociais e de natureza fonética quanto à expressão formal da concordância.

Espera-se, por fim, que esta descrição contribua para o controle mais refinado da saliência fônica, a fim de que se avancem os conhecimentos dos padrões de concordância do Português - fenômeno de grande importância no debate sobre as origens da variedade brasileira.

\section{Agradecimentos}

Esta fase da pesquisa, desenvolvida durante minha Iniciação Científıca, foi financiada pelo CNPq, agência a que destino os agradecimentos deste trabalho.

\section{REFERÊNCIAS}

BARRETO, F. A concordância verbal de $3^{a}$ pessoa do plural no Português Europeu. 2014. Dissertação (Mestrado em Letras Vernáculas) - Faculdade de Letras, Universidade Federal do Rio de Janeiro, Rio de Janeiro, 2014.

CHAVES, R. Princípio de Saliência Fônica: isso não soa bem. Letrônica, Porto Alegre, v. 7, n. 2, p. 522-550, 2014.

GUY, G. Linguistic variation in Brazilian Portuguese: aspects of phonology, syntax and language history. 1981. Tese (Doutorado) - University of Pennsylvania, Pennsylvania, 1981.

LABOV, W. Some sociolinguistic principles. In: PAULSTON, C. P.; TUCKER, G. R. Sociolinguistics: the essential readings. Oxford: Blackwell, 2003. p. 235-250.

LEMLE, M.; NARO, J. A. Competências básicas do português [Relatório de pesquisa]. Rio de Janeiro: Fundação Movimento Brasileiro de Alfabetização, 1977.

MONGUILHOTT, I. Estudo sincrônico e diacrônico da concordância verbal de terceira pessoa do plural no PB e no PE. 2009. Tese (Doutorado em Linguística) - Universidade Federal de Santa Catarina, Florianópolis, 2009. 
MONGUILHOTT, I. Variação na concordância verbal de terceira pessoa do plural na fala dos florianopolitanos. 2001. Dissertação (Mestrado em Linguística) - Universidade Federal de Santa Catarina, Florianópolis, 2001.

NARO, A. J. The social and structural dimensions of a syntatic change. LSA, Language, v. 57, n. 1, p. 63-98, 1981.

NARO A. J.; SCHERRE, M. M. Estabilidade e mudança linguística em tempo real: a concordância de número. In: PAIVA, M. C.; DUARTE, M. E. (org.). Mudança em tempo real. Rio de Janeiro: Contra Capa/FAPERJ, 2003. p. 47-62.

NARO, A. J.; SCHERRE, M. M. Fluxos e contrafluxos: movimentos sociolinguísticos da comunidade de fala brasileira. In: MOLLICA, M. C. (org.). Usos da linguagem e sua relação com a mente humana. Rio de Janeiro: Tempo Brasileiro, 2010. p. 79-90.

SANKOFF, D.; TAGLIAMONTE, S.; SMITH, E. Goldvarb X: a variable rule application for Macintosh and Windows. 2005. Disponível em: http://individual.utoronto.ca/ tagliamonte/goldvarb.html. Acesso em: 5 out. 2020.

VIEIRA, S.; BRANDÃO, S.; GOMES, D. A expressão fonética de terceira pessoa do plural no Português do Brasil: uma agenda de pesquisa para o tratamento da variável saliência fônica. In: VIEIRA, S. R. (org.). A concordância verbal em variedades do Português: a interface Fonética-Morfossintaxe. v. 1. Rio de Janeiro: Vermelho Marinho/FAPERJ, 2015. p. 104-155.

VIEIRA, S.; BRANDÃO, S. CORPORAPORT: variedades do Português em análise. Rio de Janeiro: Faculdade de Letras - UFRJ. Disponível em: http://www.corportaport.letras.ufrj. br. Acesso em: 05 out. 2020.

WEINREICH, U.; LABOV, W.; HERZOG, M. Fundamentos empíricos para uma teoria da mudança linguística. Tradução Marcos Bagno. São Paulo: Parábola Editorial, 2006 [1968]. 